\title{
Intergroup contact moderates the influence of social norms on prejudice
}

Group Processes \& Intergroup Relations
$1-23$
C) The Author(s) 2019
Article reuse guidelines:
sagepub.com/journals-permissions
DOI: $10.1177 / 1368430219839485$
journals.sagepub.com/home/gpi

(\$SAGE

\author{
Emilio Paolo Visintin, ${ }^{1}$ (D) Eva G. T. Green, ${ }^{1}$ \\ Juan Manuel Falomir-Pichastor ${ }^{2}$ (D) and Jacques Berent ${ }^{2}$
}

\begin{abstract}
While previous research has examined social norms and intergroup contact as predictors of prejudice, there is limited research on their interplay in shaping intergroup attitudes. The results of five studies using correlational and experimental methods in different intergroup contexts consistently showed that the influence of intolerant (vs. tolerant) social norms on prejudice is reduced for people who have contacts with outgroup members. Studies 4-5 further showed that threat perceptions mediate the interaction effects between norms and contact on prejudice. Overall, the research program suggests that intergroup contact is a potent tool for reducing conformity to intolerant and antiegalitarian norms.
\end{abstract}

\section{Keywords}

intergroup contact, intergroup threat, prejudice, social norms

Paper received 18 April 2018; revised version accepted 1 March 2019.

While Western societies are becoming ethnically and culturally more and more diverse, this phenomenon is not always accompanied by increased tolerance between different ethnic communities. Intergroup relations in Western societies are indeed characterized by complex and sometimes opposing drives. On the one hand, several lines of research have proposed that blatant prejudice and discrimination against social minorities (such as immigrants or ethnic minorities) have progressively become socially unacceptable, and have been replaced by more subtle and hidden forms of prejudice (e.g., Dovidio \& Gaertner, 2004; McConahay, 1986; Pettigrew \& Meertens, 1995). This shift in social norms implies condemning explicit prejudice and prescribing a politically correct society. On the other hand, recent years have been characterized by blatantly intolerant viewpoints toward social minorities appearing in political discourse, public opinion, and mass media (e.g., Mudde, 2013; Mutz \& Goldman, 2010). The raise of extreme right and anti-immigration political parties is an illustration

\footnotetext{
${ }^{1}$ University of Lausanne, Switzerland

${ }^{2}$ University of Geneva, Switzerland

Corresponding author:

Emilio Paolo Visintin, Department of Humanities, University of Ferrara, via Paradiso 12, I-44121, Ferrara, Italy.

Email: emiliop.visintin@gmail.com
} 
of this phenomenon (e.g., Greven, 2016). Thus, a complex and mixed normative climate toward social minorities characterizes current-day Western societies, where people are often exposed to messages transmitting either tolerant or intolerant social norms about immigration and social minorities. These norms, in turn, are likely to affect people's prejudice (see Tankard \& Paluck, 2016).

Social norms convey group standards about socially accepted and expected behaviors, attitudes, and values. Norms thus refer to beliefs about what ingroup members do and think (descriptive norms) and beliefs about what ingroup members consider an appropriate behavior (injunctive norms; Cialdini, Kallgren, \& Reno, 1991). Focusing on intergroup relations, social norms towards social minorities can range from intolerant to tolerant norms. Intolerant norms prescribe negative intergroup relations and acceptance of discrimination and intolerance, and describe the ingroup as discriminatory and prejudiced against social minorities. Tolerant norms instead prescribe intergroup tolerance and positive intergroup relations condemning discrimination, and describe the ingroup as having favorable attitudes toward social minorities. Although people tend to conform to social norms (be they tolerant or intolerant; e.g., Crandall, Eshleman, \& O’Brien, 2002; Jetten, Spears, \& Manstead, 1996), they do not systematically do so (e.g., Tankard \& Paluck, 2016). Indeed, both individual and situational factors shape the influence of norms on prejudice. For example, conformity to social norms appears to be a function of norm salience (e.g., Blanchard, Crandall, Brigham, \& Vaughn, 1994; Cialdini et al., 1991) or identification with one's own social group (e.g., Jetten, Postmes, \& McAuliffe, 2002). Further, conformity is reduced when people consider norms inappropriate (see Jetten \& Hornsey, 2014; Packer \& Chasteen, 2010), be it because such norms mismatch personal values (e.g., Hornsey, Majkut, Terry, \& McKimmie, 2003), personal interests (Rios, Wheeler, \& Miller, 2012), or group interests (e.g., Falomir-Pichastor, Muñoz-Rojas, Invernizzi, \& Mugny, 2004).

In this research, we investigated how interpersonal contact with outgroup members (i.e., intergroup contact; Allport, 1954; Pettigrew \& Tropp, 2006) moderates the influence of social norms on prejudice. We conducted five studies, with varying intergroup contexts and methodologies, examining national majority members' prejudice towards immigrants and ethnic minorities. Across all studies, we tested the hypothesis that national majority members with only few personal contact experiences with minorities should be particularly susceptible to intolerant social norms (i.e., would conform to a greater extent), while those with frequent contact with outgroup members should be less influenced by intolerant norms. In the last two studies, we additionally focused on the mediating role of intergroup threat in this process.

\section{The Interplay Between Social Norms and Intergroup Contact on Intergroup Attitudes}

Contact with outgroup members is considered one of the most powerful means to reduce prejudice, and a large amount of empirical evidence supports this claim (e.g., Brown \& Hewstone, 2005; for a meta-analysis, see Pettigrew \& Tropp, 2006). Research has distinguished between different intergroup contact forms, such as contact quantity (i.e., the amount and frequency of contacts), contact quality (i.e., the pleasantness and intimacy of contacts), and cross-group friendships (i.e., having friends who are members of the outgroup). Importantly, all these contact facets are related to prejudice reduction (e.g., Tausch, Tam, Hewstone, Kenworthy, \& Cairns, 2007 for contact quantity and quality; Swart, Hewstone, Christ, \& Voci, 2011 for cross-group friendships; see also Davies, Tropp, Aron, Pettigrew, \& Wright, 2011, for a meta-analysis on cross-group friendships). Research has further shown that intergroup contact reduces negative intergroup attitudes because it helps to develop deep interpersonal knowledge (Pettigrew \& Tropp, 2008) and helps to reduce threatening perceptions of outgroups (Pettigrew, Christ, Wagner, \& Stellmacher, 2007; Tausch et al., 2007). 
In the present research, we contended that intergroup contact moderates the influence of social norms. Here we predicted that intergroup contact reduces individuals' conformity to intolerant norms (Hypothesis 1). Specifically, we expected that intolerant norms mostly increase prejudice among individuals with low intergroup contact experiences (e.g., contact quantity, contact quality, cross-group friendships, etc.). Conversely, among those with high intergroup contact, conformity to intolerant social norms should be reduced.

This hypothesis is supported by previous research showing that intergroup contact can offset the impact of factors that foster prejudice. For example, analyzing the effects of ethnic diversity on prejudice among the White British majority, Laurence (2014) found that living in ethnically diverse communities in the UK was related to negative intergroup attitudes, but only for those who did not have personal contact with members of other ethnic groups (see also Schmid, Al Ramiah, \& Hewstone, 2014). Furthermore, two studies conducted in Switzerland showed that the negative association between hierarchy enhancing ideologies (i.e., social dominance orientation) and support for immigrant rights is reduced for Swiss citizens with contact with immigrants (Visintin, Berent, Green, \& Falomir-Pichastor, 2019). Thus, intergroup contact buffers the effects of antecedents of prejudice, which suggests that it should also reduce conformity to intolerant norms.

Our main prediction is also informed by attitude research and, more specifically, the distinction between direct versus indirect experiences with attitude objects (e.g., Fazio, 1990; Fazio, Zanna, \& Cooper, 1978). Research has shown that attitudes based on personal experience (i.e., direct experience) tend to be particularly strong and resistant to social influence (Howe \& Krosnick, 2017). In the context of intergroup contact and social norms, this suggests that attitudes based on personal intergroup contact should be quite strong and resistant to change (see Vonofakou, Hewstone, \& Voci, 2007). Attitudes based on personal experience may even be stronger than attitudes based on social norms. Indeed, intergroup contact provides firsthand, direct experiences with (and information about) outgroup members. Social norms, in turn, inform individuals about fellow ingroup members' attitudes toward outgroup members, and therefore only constitute second-hand, indirect experience with (and information about) the outgroup. Thus, while people might conform to (intolerant) social norms because of the (negative) information these norms convey about immigrants, by providing individuals with first-hand (and positive) information about immigrants, intergroup contact should reduce the influence of secondary social norms. This reasoning applies to different contact facets, such as contact quantity, contact quality, and crossgroup friendships. Indeed, all these contact facets constitute direct, primary experiences with outgroup members associated to reduced prejudice (e.g., Davies et al., 2011; Pettigrew \& Tropp, 2006).

This prediction is also consistent with research showing that conformity is reduced when familiarity with the target outgroup is increased. Indeed, Sechrist and Stangor (2007) found that people's perceptions of their own and others' attitudes toward social groups converge more for groups with whom they are unfamiliar than for groups with whom they have had interactions in the past. Other research has investigated the role of intergroup contact in shaping the transmission of prejudice from parents to children. Adolescents' intergroup contact experiences (Dhont \& van Hiel, 2012) and the importance adolescents attributed to intergroup contact (Rodríguez-García \& Wagner, 2009) buffered the impact of parents' prejudice on adolescents' prejudice. Finally, studying interminority relations, Mähönen, Ihalainen, and Jasinskaja-Lahti (2013) found an interaction between contact quality and family and peer norms on prejudice, suggesting that immigrant adolescents who perceived their family and peers as prejudiced against other immigrant groups were likely to express more prejudice, but only when the quality of their contacts with members of other immigrant groups was low (see also Jasinskaja-Lahti, Mähönen, \& Liebkind, 2011, for similar findings when analyzing minority-majority relations). ${ }^{1}$

Although these studies are enlightening, their correlational nature allows for limited conclusions regarding causality of effects. Furthermore, these 
studies were conducted on samples of adolescents (Dhont \& van Hiel, 2012; Jasinskaja-Lahti et al., 2011; Mähönen et al., 2013; Rodríguez-García \& Wagner, 2009) or of university students (Sechrist \& Stangor, 2007) in a single intergroup context. These limitations thus question the generalizability of the findings described before. Moreover, previous studies have not provided evidence of the processes by which the interplay between norms and contact impacts prejudice.

In order to overcome these limitations and to further disentangle the interplay between norms and contact on prejudice, we conducted the present research program including analyses of large-scale surveys and of different intergroup contexts which will allow us to draw conclusions about the generalizability of the effects under study. We also included experimental studies in order to determine the causality of these effects. Finally, to better understand the processes at play, we additionally investigated the potentially mediating role of intergroup threat.

\section{The Mediating Role of Intergroup Threat}

Based on intergroup threat theory (Stephan, Ybarra, \& Rios Morrison, 2009), we proposed that the perceived threat outgroup members pose to the ingroup mediates the interplay between norms and contact on intergroup attitudes. Indeed, prior research has amply demonstrated that outgroups can be seen as a threat to the values, identity, safety, and economic well-being of the ingroup, and that intergroup threat perceptions are one of the main precursors of prejudice (Riek, Mania, \& Gaertner, 2006; Stephan et al., 2009). Stephan et al. (2009) argued that norms promoting intolerant and negative intergroup relations may activate and exacerbate feelings of threat, which in turn heighten prejudice (Riek et al., 2006). In this vein, previous research has shown that intolerant norms increase intergroup bias especially when intergroup threat is salient (Falomir-Pichastor, Gabarrot, Mugny, \& Nurra, 2007; Falomir-Pichastor \& Mugny, 2009), suggesting that intergroup threat might mediate the association between intolerant norms and prejudice. There is also evidence that intergroup contact provides valuable information that allows disconfirming and consequently reducing threat perceptions (e.g., Pettigrew et al., 2007; Tausch et al., 2007). Indeed, intergroup threat is one of the well-established mediators of the association between contact and reduced prejudice (e.g., Pettigrew et al., 2007; Tausch et al., 2007).

Hence, following our rationale, personal experiences with outgroup members provide more valuable information about potential threats posed by outgroup members than the surrounding norms, and intergroup contact should reduce the influence of norms on threat perceptions. Accordingly, we predicted that perceived intergroup threat acts as a mediator of the interaction between intergroup contact and norms on intergroup attitudes. Specifically, we hypothesized that intolerant norms are associated with prejudice via threat perceptions only or mainly for people with no or low intergroup contact, while the norms-threat-prejudice association should be weaker for people with frequent intergroup contact (Hypothesis 2).

\section{Overview of the Studies}

We tested our main prediction that intergroup contact buffers the influence of intolerant social norms on prejudice (Hypothesis 1) in five studies. In Studies 4 and 5, we also tested the mediating role of intergroup threat (Hypothesis 2). Throughout these studies, different conceptualizations and operationalizations of both social norms and intergroup contact were used. Specifically, in Study 1 we considered perceived norms, that is, the degree to which ingroup members are perceived prejudiced against outgroup members and the perceived acceptability of prejudice in a given intergroup context. In Study 2, we analyzed actual prevailing norms, that is, attitudes and prejudice toward the outgroup reported by other ingroup members. In Studies 3-5, we focused on experimentally induced norms. Intergroup contact was measured in Studies 1-4, and experimentally manipulated with the imagined contact paradigm (Crisp \& Turner, 2012) in Study 5. Our 
hypotheses were tested in the context of national majorities' prejudice toward ethnic and immigrant minorities. The studies were conducted in different intergroup contexts with the aim of providing external validity to our tests.

\section{Study 1}

Study 1 is a correlational study conducted in Bulgaria examining the attitudes of the ethnic Bulgarian majority towards the Bulgarian Turkish minority (an ethnic minority facing discrimination in current-day Bulgarian society; e.g., Vassilev, 2010). Following Hypothesis 1, we expected that a greater perception of intolerant norms would be associated with more prejudice against Bulgarian Turks. However, this relationship should be weaker for ethnic Bulgarians with frequent contact with Bulgarian Turks, as compared to ethnic Bulgarians with low contact with Bulgarian Turks.

\section{Participants and Method}

The data were part of a research project examining interethnic attitudes in Bulgaria (Green \& Zografova, 2014). As the focus was on majority attitudes, we used data gathered on ethnic Bulgarian majority members ( $N=576 ; 50 \%$ female; $\left.M_{\text {age }}=45.00, S D_{\text {age }}=17.34\right)$. Respondents were recruited with a cluster sampling method, with each cluster composed of eight respondents. The sample was stratified by gender, age, and urban versus rural residence, and points of data collection were selected based on data from the Bulgarian National Statistical Institute. The questionnaires were administered individually in faceto-face interviews by professional interviewers. Respondents were provided with the necessary information for informed consent, as well as guaranteed anonymity and the right to withdraw from the survey at any time. Descriptive statistics and correlations between variables are provided in the supplementary material. ${ }^{2}$

Social norms. Two items assessed the perception of descriptive ("Ethnic Bulgarians have negative feelings toward Bulgarian Turks") and prescriptive
("In Bulgaria it is acceptable to express negative feelings toward Bulgarian Turks") norms about relations between ethnic Bulgarians and Bulgarian Turks. Responses ranged from 1 (completely disagree) to 5 (completely agree). The two items (SpearmanBrown reliability statistic for a two-item measure: $\rho=.81$ ) were averaged to form a composite score where higher values indicate more intolerant perceived norms.

Intergroup contact. Two items measured intergroup contact: "How often do you have brief interactions (for example exchanging a couple of words on the bus/train, in the street, in shops, in the neighborhood and so on) with Bulgarian Turks?" $(1=$ never, 5 = every day; adapted from Schmid et al., 2014) and "How many Bulgarian Turks do you know well?" (1 = none, $4=$ a lot, adapted from Voci \& Hewstone, 2003). These two items were standardized because of the different response scale and subsequently averaged to create a composite score with higher values reflecting more contact $(\rho=.87)$.

Prejudice. Respondents rated their agreement with six items assessing blatant prejudice towards Bulgarian Turks (e.g., "Some aspects of Turkish life are typical examples of a backward culture"; Leidner, Castano, Zaiser, \& Giner-Sorolla, 2010; McConahay, 1986) on a 5-point scale (1 = completely disagree, $5=$ completely agree). Responses were averaged to create a reliable composite score with higher values representing more prejudice $(\alpha=.83)$.

\section{Results and Discussion}

To test the interactive effects between intolerant norms and intergroup contact on prejudice, we ran a regression analysis including perceived intolerant norms, intergroup contact, and the interaction between these two variables as predictors, while using prejudice as outcome variable. Predictors were centered before running the regression analysis (Aiken, West, \& Reno, 1991). The regression analysis was conducted with Mplus using the Complex command that controls for nonindependence of data due to the 
Table 1. Regression analyses of the effects of contact, social norms, and their interactions on prejudice (Studies 1,2 , and 3).

\begin{tabular}{lccc}
\hline & Study 1 & Study 2 & Study 3 \\
\hline Intercept & $2.86(0.19)^{* * *}$ & $2.69(0.04)^{* * *}$ & $2.69(0.09)^{* * *}$ \\
& {$[2.48,3.24]$} & {$[2.60,2.78]$} & {$[2.51,2.88]$} \\
Intergroup contact & $-0.18(0.06)^{* * *}$ & $-0.20(0.01)^{* * *}$ & $-0.46(0.11)^{* * *}$ \\
& {$[-0.29,-0.07]$} & {$[-0.23,-0.18]$} & {$[-0.69,-0.24]$} \\
Intolerant norms & $0.34(0.05)^{* * *}$ & $0.32(0.06)^{* * *}$ & $0.24(0.09)^{*}$ \\
& {$[0.25,0.44]$} & {$[0.20,0.45]$} & {$[0.06,0.43]$} \\
Intergroup Contact $\times$ Intolerant & $-0.14(0.05)^{* *}$ & $-0.05(0.02)^{*}$ & $-0.27(0.11)^{*}$ \\
Norms & {$[-0.24,-0.04]$} & {$[-0.10,-0.004]$} & {$[-0.50,-0.04]$} \\
Explained variance & $R^{2}=.28$ & Individual-level $R^{2}=.14$ & $R^{2}=.31$ \\
& & Country-level $R^{2}=.64$ & \\
\hline
\end{tabular}

Note. Unstandardized B coefficients. Standard errors are reported within parentheses and 95\% confidence intervals are reported within brackets. Contact was measured in all three studies. Social norms were measured in Studies 1 and 2 and experimentally manipulated in Study 3. In Studies 1 and 2 conducted among a general population, we controlled for gender, age, education, and perceived economic situation.

${ }^{*} p<.05{ }^{* *} p<.01{ }^{* * *} p \leqslant .001$.

clustered nature of the sample (Muthén \& Muthén, 1998-2012). Given that we analyzed data from a large-scale survey administered to a general adult population, we also controlled for sociodemographic characteristics which might affect attitudes toward immigrants and ethnic minorities (i.e., gender, age, educational level, and perceived economic situation; Ceobanu \& Escandell, 2010).

Table 1 shows results of the regression analysis. As hypothesized, the interaction between norms and contact on outgroup prejudice was significant and explained $2.1 \%$ of the variance. Decomposition of the interaction showed that the positive relationship between intolerant norms and prejudice was stronger for respondents with relatively low levels of intergroup contact $(-1 S D), B=0.47, S E$ $=0.06, p<.001,95 \%$ CI $[0.35,0.59]$ than for respondents with relatively high levels of intergroup contact $(+1 S D), B=0.21, S E=0.07, p=$ $.003,95 \%$ CI $[0.07,0.35]$ (see Figure 1). Moreover, contact was associated with reduced prejudice for respondents who perceived norms as intolerant $(+1 S D), B=-0.31, S E=0.08, p<.001,95 \% \mathrm{CI}$ $[-0.47,-0.15]$, while the association between contact and prejudice was not significant for respondents who perceived norms as tolerant $(-1 S D)$, $B=-0.04, S E=0.06, p=.481,95 \%$ CI $[-0.17$,

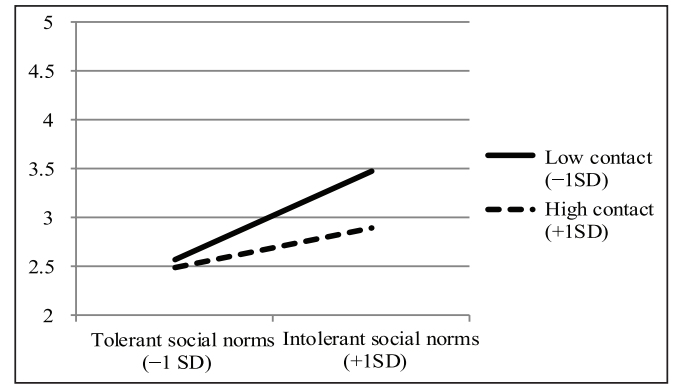

Figure 1. Prejudice as a function of social norms and intergroup contact: Study 1.

0.08]. Therefore, and as expected, intergroup contact reduced conformity to intolerant social norms on anti-Bulgarian Turks prejudice. A second study was designed to provide further evidence of this moderation effect.

\section{Study 2}

While in Study 1 we tested whether intergroup contact moderates conformity to perceived social norms in one country, in Study 2 we focused on norms actually prevailing at the national level. Further, we extended to a cross-national comparison. Recent social psychological research has considered aggregated attitudes and beliefs and their variations 
between contexts as indicators of contextual shared norms. For example, van Assche, Roets, De Keersmaecker, and van Hiel (2017) employed aggregated regional- and country-level scores of right-wing ideology as indicators of a right-wing sociocultural climate (see also Christ et al., 2014). In this vein, we analyzed secondary data of the European Social Survey (ESS; http:/ / www.europeansocialsurvey.org). We derived country-level norms from aggregated anti-immigration beliefs from ESS Round 5 (ESS, 2010). For each country, we calculated the average anti-immigration beliefs of a representative sample of the national population (ESS Round 5) and considered them as indicators of existing norms about immigration. Thus, norms were not assessed as individual-level perceptions, but rather as shared beliefs toward immigration of the citizens in a country. We assessed individuals' contact experiences and prejudice with data from ESS Round 7 (ESS, 2014) immigration module. ${ }^{3}$ Then, we examined the interplay between country-level norms and intergroup contact on prejudice. We expected that country-level norms would be associated with prejudice, so that citizens in countries with prevailing intolerant norms would be more likely to have higher prejudice levels than citizens in countries with prevailing tolerant norms. Following Hypothesis 1, this relationship should be reduced among citizens with relatively more contact with immigrant and ethnic minorities.

\section{Participants and Method}

We analyzed ESS Round 7 data, and included in the sample respondents who were citizens of the country of data collection $(N=38,075$ citizens from 21 countries; $53 \%$ female; $M_{\text {age }}=49.58$, $\left.S D_{\text {age }}=18.82\right)$.

Social norms. We assessed social norms at the country level by using data from ESS Round 5 (for the 21 countries included in ESS Round 7; $N=38,555$ citizens). We used three questions from the core module of the survey measuring anti-immigrant beliefs ("Would you say it is generally bad or good for [country]'s economy that people come to live here from other countries?";
'Would you say that [country]'s cultural life is generally undermined or enriched by people coming to live here from other countries?"; and "Is [country] made a worse or a better place to live by people coming to live here from other countries?"). The response scale ranged from 0 corresponding to the negative pole (bad, undermined, worse) to 10 corresponding to the positive pole (good, enriched, better). We averaged reverse-coded answers to create a composite score of anti-immigrant beliefs $(\alpha=.85$; $\alpha$ s by country ranged from .76 to .91). Next, we averaged the anti-immigrant beliefs of the citizens within each country. While these items have been previously used to detect prejudice toward immigrants at the individual level of analysis (e.g., Green, 2009), here we used these answers to create a country-level aggregated score, which represents the extent to which citizens in a given country believe that immigration has negative consequences. Accordingly, this score was treated as an indicator of prevailing antiimmigration norms (for similar procedures, see van Assche et al., 2017).

Intergroup contact. Intergroup contact in the form of cross-group friendships was assessed through the following question: "Do you have any close friends who are of a different race or ethnic group from most [respondent's country] people?" (Response options were $1=$ yes, several; $2=$ yes, a few; $3=$ no, none at all). We reverse-coded answers to this question so that a higher score represented more intergroup contact.

Generalized prejudice. Prejudice toward six outgroups was assessed with six questions asking whether, according to the respondents' point of view, their country should allow people to come to live in the country: "To what extent do you think [respondent's country] should allow [outgroup members] to come and live here?" $(1=$ allow many to come and live here, $4=$ allow none). The outgroups were people of the same race or ethnic group as most (country) people, people of a different race or ethnic group from most (country) people, people from the poorer countries outside Europe, Jewish people from other countries, 
Muslims from other countries, and Gypsies from other countries. ${ }^{4}$ These items were chosen as they tap personal negative reactions toward receiving several immigrant and ethnic minority groups (see e.g., Thomsen \& Rafiqi, 2018). Responses were averaged to create a reliable composite score of generalized prejudice $(\alpha=.90 ; \alpha$ s by country ranged from .72 to .94; see supplementary material for mean scores and correlations between contact and prejudice by country).

\section{Results and Discussion}

Because respondents were nested within countries, and norms were assessed at the country level, we conducted multilevel regression analyses using maximum likelihood estimation (Mplus), with countries as between-level units of analysis. Generalized prejudice varied between countries $\left(\mathrm{ICC}=.16, \sigma^{2}=0.09, \mathrm{SE}=0.03, p=.001\right)$, confirming the suitability of multilevel modeling.

Generalized prejudice was regressed on intergroup contact and on individual-level control variables (gender, age, years of education, perceived economic situation; within-level predictors), on norms (between-level predictor), and on the interaction between norms and contact (cross-level interaction). Before performing multilevel regression analysis, norms were grand-mean-centered and intergroup contact was group-mean-centered (see Enders \& Tofighi, 2007, for centering procedures in cross-level interactions).

As expected, intergroup contact significantly moderated the effect of social norms on generalized prejudice (see Table 1). Decomposition of this interaction showed that anti-immigration norms were positively associated with respondents' generalized prejudice, but the association was stronger for respondents with low $(-1 S D)$ intergroup contact, $B=0.36, S E=0.07,95 \% \mathrm{CI}$ $[0.23,0.49], p<.001$, than for respondents with high $(+1 S D)$ intergroup contact, $B=0.29$, SE $=0.07,95 \%$ CI $[0.16,0.42], p<.001$ (see Figure 2). Further, the negative association between contact and prejudice was stronger in countries with intolerant prevailing norms ( $+1 S D), B=-0.24$, $S E=0.02, p<.001,95 \%$ CI $[-0.28,-0.20]$,

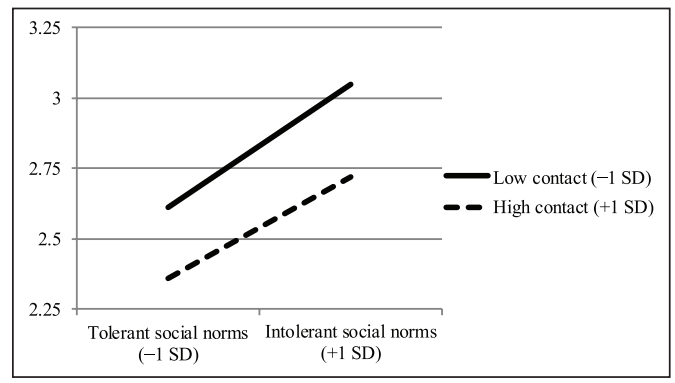

Figure 2. Generalized prejudice as a function of social norms and intergroup contact: Study 2.

than in countries with tolerant prevailing norms $(+1 S D), B=-0.17, S E=0.02, p<.001,95 \%$ CI $[-0.21,-0.13] .^{5}$

Thus, Study 2 showed that people living in countries where the general population is prejudiced against immigrants (i.e., in countries where intolerant, antiegalitarian norms prevail) are likely to express more prejudice compared to people living in countries where the population has low levels of prejudice (i.e., in countries where tolerant, egalitarian norms prevail), but this association is reduced for those with more frequent intergroup contacts. Consistent with the results of Study 1, Study 2 provided additional support for the main hypothesis, according to which contact specifically buffers conformity to intolerant norms. Furthermore, Study 2 used a different methodological approach, analyzing correlates of actual prevailing norms at the country level and conducting a cross-country comparison on nationals' attitude towards immigrants, adopting a multilevel approach. Given the correlational nature of the data of the two first studies, we ran additional quasi-experimental (Studies 3 and 4) and experimental (Study 5) studies to provide stronger empirical support for our contention.

\section{Study 3}

Study 3 tested the main hypothesis while overcoming the limitations due to the correlational nature of Studies 1 and 2: Intergroup contact was initially measured and then we experimentally manipulated 
tolerant versus intolerant norms about intergroup relations. We expected conformity to intolerant norms (i.e., expressing more prejudice) to be lower among respondents with higher intergroup contact. This hypothesis was tested in Switzerland and considered intergroup relations between Swiss citizens and immigrants. Switzerland is characterized by a large foreign resident population (24.6\%; Swiss Federal Statistical Office [SFSO], 2017) and consequently by opportunities for intergroup contact, but also by a strong anti-immigration stance among Swiss nationals (e.g., Nicolet \& Sciarini, 2006), making Switzerland an interesting context for testing our predictions.

\section{Participants and Procedure}

Before data collection, we determined a sample size of about 40 respondents by experimental condition $\left(N_{\text {total }}=80\right)$. Anticipating that some participants would be excluded from the analyses (e.g., because the Swiss-French population was the target ingroup in the experimental manipulation of norms, only Swiss-French respondents were kept in data analysis), we recruited 95 participants in cafeterias of a Swiss-French university and invited them to individually complete a questionnaire. Participants were randomly assigned to one of two experimental conditions (tolerant vs. intolerant norms). Afterwards, participants were thanked and debriefed. The debriefing procedure was the same across Studies 3-5. The ethics committee of one of the host universities approved Studies 3-5. ${ }^{6}$ After removal of other than Swiss-French participants, 75 were retained for analyses $(69 \%$ female; $M_{\text {age }}=24.40, S D_{\text {age }}=5.56$ ).

Intergroup contact. Intergroup contact was measured at the beginning of the questionnaire. Participants were asked to report their contact experiences with immigrants through four items (e.g., "Do you have daily contact with immigrants, for example by exchanging a few words on the bus/train, on the street, in shops, in the neighborhood or other places?"; $1=$ never, $5=$ very often; "How many of your friends are immigrants?" $1=$ none, $5=$ many; see Schmid et al.,
2014; Voci \& Hewstone, 2003). Items were averaged to create a composite score with higher values representing more contact $(\alpha=.84)$.

Social norms. We subsequently manipulated social norms by adapting the experimental manipulation by Falomir-Pichastor et al. (2004). Participants were informed about the results of a fictitious survey conducted in the French-speaking part of Switzerland. The summary of results of this survey was provided through bar charts representing the percentage of "yes," "no," and "don't know" responses to six questions asked to the majority of the Swiss-French population about immigrants. Examples of these questions are, "Do you agree that Swiss citizens should be favored over immigrants?" and "Should Swiss policies toward immigration be more or less favorable towards immigrants?" Participants were randomly assigned to one of two experimental conditions and, depending on the condition, the bar charts showed that the strong majority of the Swiss-French people consistently favored immigration and an equal treatment between Swiss and immigrants (tolerant norms condition) or was against immigration and preferred advantages for the Swiss population over immigrants (intolerant norms condition).

As a manipulation check, participants were thereafter asked the following question: "In your view, do most of Swiss-French population support an equal treatment between Swiss and immigrants?" Response options ranged from 1 (not at ald) to 7 (absolutely). Respondents in the tolerant norms condition perceived more support for equality among the Swiss-French population $(M$ $=4.79, S D=1.61)$ than respondents in the intolerant norms condition $(M=2.70, S D=1.33)$, $t(73)=6.10, p<.001$, suggesting that the experimental manipulation was successful.

Prejudice. At the end of the questionnaire we assessed prejudice with a single question asking participants about their attitudes toward immigrants in Switzerland $(1=$ extremely unfavorable, 7 $=$ extremely favorable). Responses were reversecoded so that higher values indicate more antiimmigrant prejudice (see supplementary material 


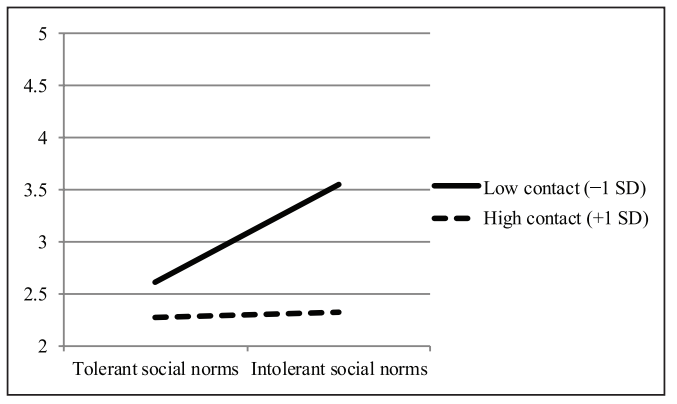

Figure 3. Prejudice as a function of social norms and intergroup contact: Study 3.

for means and standard deviations by experimental condition).

\section{Results and Discussion}

We conducted a regression analysis to examine whether intergroup contact buffered the effect of exposition to intolerant norms. Social norms were coded as $-1=$ tolerant, $+1=$ intolerant. The score of intergroup contact was centered prior to analysis (Aiken et al., 1991). Anti-immigrant prejudice was regressed on norms, contact, and their product. As expected, the interaction between the experimental condition and contact yielded a significant effect on prejudice (see Table 1) and explained $4.6 \%$ of the variance. Decomposition of the interaction showed that exposure to intolerant (vs. tolerant) norms increased prejudice for respondents with relatively low contact with immigrants ( $-1 S D), B=0.47$, SE $=0.13, p<.001,95 \%$ CI $[0.20,0.73]$, but not for respondents with high intergroup contact $(+1 S D)$, $B=0.02, S E=0.13, p=.883,95 \%$ CI $[-0.25$, $0.28]$ (see Figure 3). Further, contact was associated with reduced prejudice for respondents exposed to intolerant norms, $B=-0.73, S E=0.15, p<.001$, $95 \%$ CI $[-1.03,-0.43]$, while the association between contact and prejudice was not significant for respondents exposed to tolerant norms, $B=$ $-0.20, S E=0.17, p=.253,95 \%$ CI [ $-0.54,0.14]$.

Using a quasi-experimental procedure, Study 3 provided support for the main hypothesis of the present article. Intergroup contact moderated the influence of intolerant social norms on prejudice against immigrants. More specifically, intolerant norms increased prejudice among Swiss who had little prior contact with immigrants, but not among those participants who had more frequent contact with immigrants.

\section{Study 4}

Study 4 tested again the main hypothesis whilst examining intergroup threat perceptions as a mediator of the predicted interplay between norms and contact on prejudice (Hypothesis 2). Specifically, in this study, we tested a mediated moderation model: Intergroup contact should moderate the effect of intolerant social norms on prejudice, and this moderation effect should further be mediated by intergroup threat perceptions.

\section{Participants and Procedure}

Unless otherwise stated, the procedure was the same as in Study 3. Study 4 was conducted in the Italian-speaking Swiss canton, which historically has been characterized by stronger anti-immigration views compared to French-speaking Switzerland (e.g., Mazzoleni \& Pilotti, 2015). Participants were high school students, who filled out the questionnaire during classes. We initially aimed to recruit a sample size similar to the one used in the previous study, but institutional constraints only allowed us to have access to 64 students. Finally, data analyses were performed on those 58 participants with Swiss nationality $(67 \%$ female; $M_{\text {age }}=18.23, S D_{\text {age }}=0.96$ ) because the Swiss population was the target ingroup of the social norms experimental manipulation. Participants were randomly assigned to one of two experimental norms conditions (tolerant vs. intolerant).

Intergroup contact. At the beginning of the questionnaire, participants completed a four-item measure of quantity of intergroup contact with immigrants adapted from Tausch et al. (2007; e.g., "How often do you have contact with immigrants at school?"; 1 = never, $5=$ very often). We averaged the four items to create a composite score with higher scores representing greater contact $(\alpha=.86)$. 
Social norms. Intolerant (vs. tolerant) norms were manipulated as in Study 3, with the fictitious survey allegedly conducted among the general Swiss population (instead of the Swiss-French part of Switzerland). As a manipulation check, we asked participants whether, in their view, most of the Swiss population supported equality between Swiss and immigrants $(1=$ not at all, $7=$ absolutely). Respondents in the tolerant norms condition perceived more support for equality $(M=$ $4.30, S D=1.49)$ than respondents in the intolerant norms condition $(M=2.00, S D=0.98)$, $t(51)=6.99, p<.001$, confirming the effectiveness of the experimental manipulation.

Intergroup threat. Threat perceptions were measured by asking respondents to rate their agreement with seven items (based on Stephan et al., 2002; e.g., "Swiss identity is threatened by the presence of immigrants" and "Immigrants have more power than what they deserve in Switzerland"; 1 = I do not agree at all, $7=I$ totally agree). A composite score was created by averaging the items. Higher scores reflect greater perceived threat $(\alpha=.80)$.

Prejudice. Finally, prejudice was measured on "feeling thermometers" on which participants indicated their attitudes toward various outgroups (immigrants, Roma, Arabs, Africans, and foreign students; responses could range from 0 (extremely unfavorable) to 100 (extremely favorable). Responses to the feeling thermometers were reverse-coded and averaged to form a composite score of generalized prejudice (for a similar procedure, see e.g., Levin et al., 2012; $\alpha=.86$; see the supplementary material for means and standard deviations by experimental condition).

\section{Results and Discussion}

First, we ran a regression analysis where generalized prejudice was regressed on the norms experimental condition $(-1=$ tolerant norms, $+1=$ intolerant norms), (centered) intergroup contact, and their product. The interaction between norms and contact significantly impacted generalized prejudice (see Table 2) and explained $5.9 \%$ of the variance. Exposure to intolerant (vs. tolerant) norms increased prejudice for respondents with low contact $(-1 S D), B=8.22, S E=3.36, p=$ $.018,95 \%$ CI $[1.47,14.96]$, but not for respondents with high contact $(+1 S D), B=-1.35, S E=3.11$, $p=.666,95 \%$ CI $[-7.59,4.89]$ (see Figure 4). Furthermore, contact was associated with reduced prejudice for respondents exposed to intolerant norms, $B=-14.04$, $S E=3.56, p<.001,95 \% \mathrm{CI}$ $[-21.18,-6.90]$, but not for respondents exposed to tolerant norms, $B=-4.53, S E=2.92, p=$ $.127,95 \%$ CI $[-10.40,1.33]$.

Next, we regressed threat on the same independent variables (see Table 2). The interaction between norms and intergroup contact had a marginally significant effect on threat $(\phi=.051)$, and explained $5.9 \%$ of the variance. Planned comparisons showed that exposure to intolerant (vs. tolerant) norms was positively related to perceived threat among respondents with low levels of contact ( $-1 S D), B=0.59, S E=0.21, p=$ $.007,95 \% \mathrm{CI}[0.16,1.02]$, but not among respondents with high levels of contact ( $+1 S D), B=$ $0.01, S E=0.20, p=.969,95 \%$ CI $[-0.39,0.40]$ (see Figure 5). Furthermore, contact was associated with reduced perceived threat for respondents exposed to intolerant norms, $B=-0.76$, SE $=0.22, p=.001,95 \% \mathrm{CI}[-1.21,-0.31]$, but not for those exposed to tolerant norm, $B=-0.18$, $S E=0.18, p=.344,95 \%$ CI $[-0.55,0.19]$.

Finally, we tested a mediated moderation model with exposure to intolerant norms as the predictor, intergroup contact as the moderator, threat as the mediator, and generalized prejudice as the dependent variable (see Table 2, column 3). We used the SPSS macro PROCESS (Hayes, 2017, Model 8) with 95\% bias-corrected bootstrapped CIs based on 5,000 bootstrap samples. As hypothesized, threat perceptions mediated the effect of the interaction between norms and contact on generalized prejudice, $B=-2.91, S E_{\text {(boot) }}=1.62,95 \% \mathrm{CI}$ $[-6.57,-0.04]$. In detail, the indirect effect of intolerant norms on generalized prejudice via threat was significant for respondents with low intergroup contact $(-1 S D), B=5.93, S E_{\text {(boot) }}=2.48,95 \% \mathrm{CI}$ $[1.08,11.03]$, but not for respondents with high 


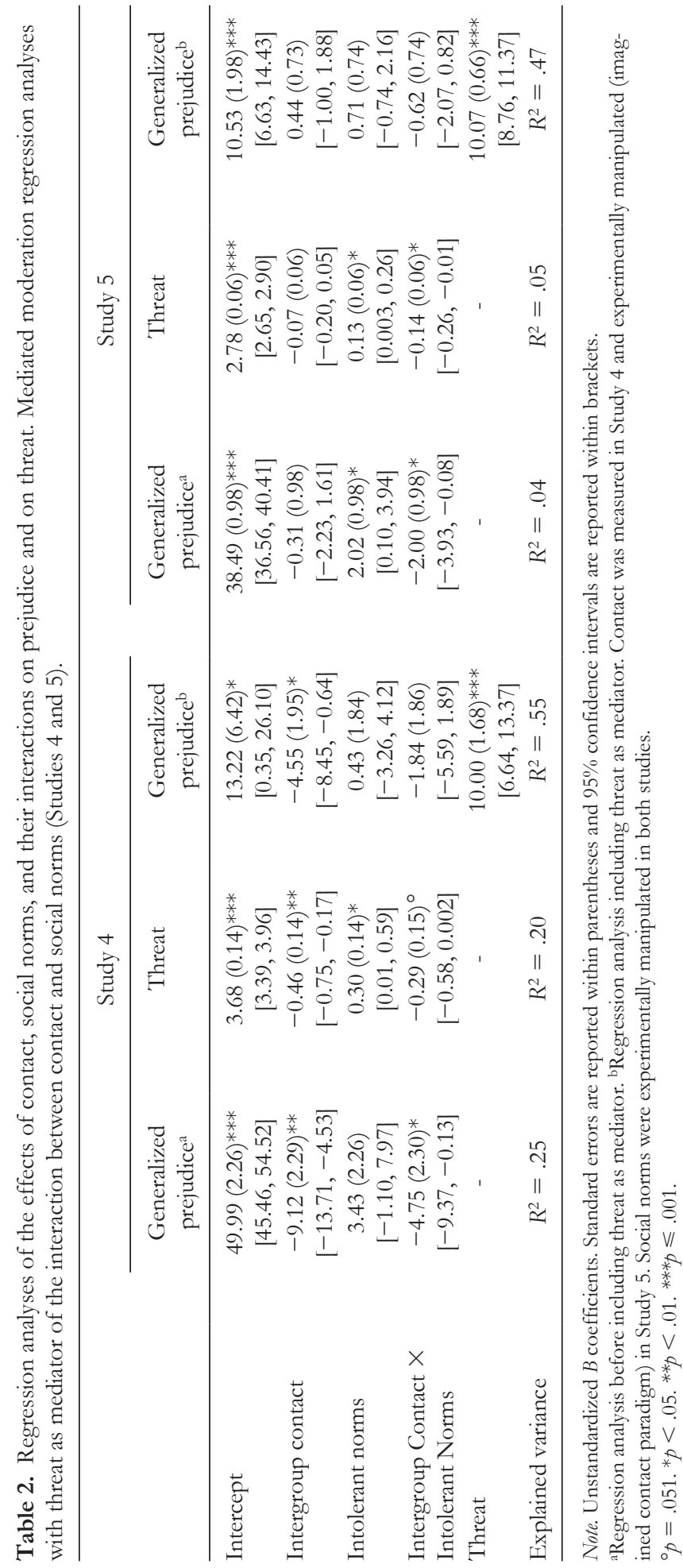




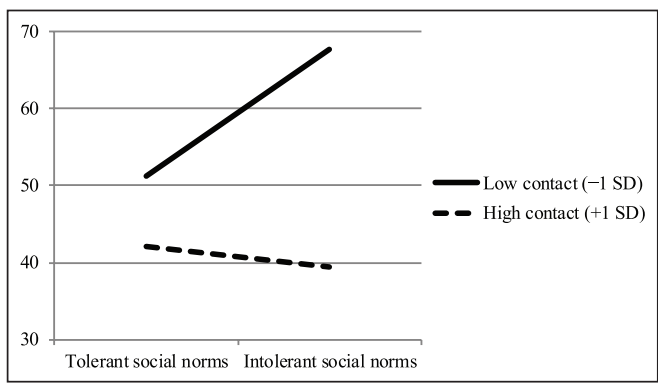

Figure 4. Generalized prejudice as a function of social norms and intergroup contact: Study 4.

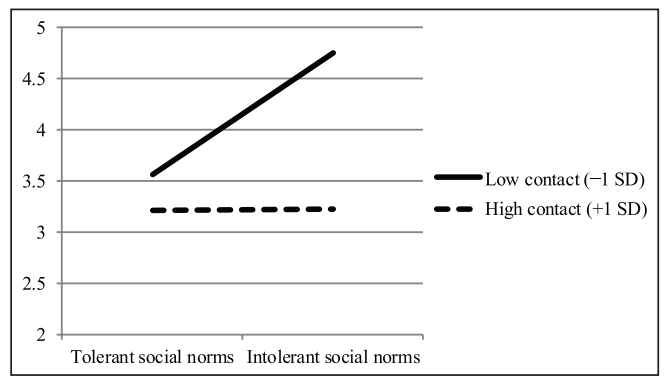

Figure 5. Intergroup threat as a function of social norms and intergroup contact: Study 4.

intergroup contact ( $+1 S D), B=0.08, S E_{\text {(boot) }}=$ $1.89,95 \%$ CI $[-3.14,4.29]$. The interaction between norms and intergroup contact on generalized prejudice was no longer significant when threat was included in the regression analysis as mediator.

Taken together, these results provided again consistent evidence in support of the main hypothesis, according to which intergroup contact moderates the influence of intolerant social norms. More specifically, exposition to intolerant (vs. tolerant) norms increased perceived threat and prejudice among people with little or no contact with outgroup members, but not among people with frequent intergroup contact. These results corroborated the findings of Studies 1-3. Most importantly, this study provided a better understanding of the processes by which this effect occurs: the interaction between social contact and norms predicts perceived intergroup threat, which in turn impacts prejudice. However, caution is needed before drawing strong conclusions from this study given the small sample size. Further, intergroup contact was only measured (rather than experimentally manipulated), which could also question the causality of the effects under study. Accordingly, a final, full experimental study was conducted.

\section{Study 5}

Study 5 aimed at replicating findings of Study 4 with a larger sample and using a full experimental research design. To experimentally manipulate intergroup contact, we employed the imagined contact paradigm (Crisp \& Turner, 2012), based on the assumption that merely imagining a positive interaction with an outgroup member can improve intergroup attitudes. Indeed, a positive imagined encounter with an outgroup member in a protected environment is likely to be experienced as a nonthreatening situation, which can activate positive feelings regarding the outgroup and regarding future interactions with outgroup members (Turner, Crisp, \& Lambert, 2007; see also Crisp \& Turner, 2012, on imagined contact as a precontact tool). Research has widely found support for prejudice reduction following imagined contact (for a meta-analysis, see Miles \& Crip, 2014). Notably, while imagined contact does not imply the occurrence of an actual, real-life intergroup encounter, it still represents a personal, direct - albeit imagined-experience with the target outgroup. Indeed, imagined contact is associated with prejudice reduction via processes similar to those involved in direct contact (see e.g., Vezzali, Crisp, Stathi, \& Giovannini, 2013, for emotional processes involved in imagined contact). Furthermore, previous research comparing the efficacy of imagined versus actual contact with outgroup members in reducing prejudice suggested that both experiences are effective at reducing prejudice (Giacobbe, Stukas, \& Farhall, 2013; Vezzali, Stathi, Crisp, \& Capozza, 2015).

We expected imagined intergroup contact to reduce the influence of intolerant norms on prejudice, as in previous studies (Hypothesis 1). Further, we predicted a mediated moderation effect: the 
interaction between norms and intergroup contact should impact on prejudice via threat perceptions (Hypothesis 2). In detail, we expected that intolerant (vs. tolerant) norms would predict prejudice via perceived threat among respondents in the control (no contact) condition, and that these effects would be reduced for respondents in the imagined contact condition.

\section{Participants and Procedure}

In the previous two studies, the predicted interaction effects explained $4.6 \%$ and $5.9 \%$ of the variance respectively, which suggests a medium effect size. Using a conservative approach, a power analysis (G*Power; Faul, Erdfelder, Lang, \& Buchner, 2007) indicated a required sample of $N=327$ in order to test an effect size of $f=.20(\alpha=.05$ and power $=.95)$ for the present experimental design. In this study, we recruited 355 students in the French-speaking region of Switzerland. Given that the Swiss-French population was the target ingroup of the social norms experimental manipulation, final analyses were run on the 300 SwissFrench participants $\left(67 \%\right.$ female; $M_{\text {age }}=20.01$, $\left.S D_{\text {age }}=2.80\right)$. Respondents were randomly assigned to one of the four conditions of a 2 (imagined contact vs. control) $\times 2$ (norms: intolerant vs. tolerant) experimental design.

Intergroup contact. We manipulated intergroup contact by adopting the imagined contact paradigm (Crisp \& Turner, 2012). In imagined contact experiments, participants are invited to imagine a positive encounter with an outgroup member or are assigned to imagination control tasks (e.g., imagining walking outdoors, an intragroup encounter). However, many variations exist between studies on imagined intergroup contact (for a review, see Miles \& Crisp, 2014), and it might be that the effects of imagined intergroup contact depend on the target outgroup (e.g., immigrants in general vs. a specific immigrant group) or on characteristics of the control condition. Thus, in the present study, two different outgroup targets were used in the imagined contact condition: roughly half of respondents were invited to imagine an encounter with an unknown immigrant on the bus, while the other half were invited to imagine an encounter on the bus with an unknown immigrant from former Yugoslavia (i.e., a harshly stigmatized immigrant group; SFSO, 2017). In the control condition, participants were either invited to imagine taking a walk outdoors or a conversation on the bus with one of their parents. To reinforce imagined contact versus control instructions, participants were then asked to write down what they had imagined (see Crisp \& Turner, 2012).

Social norms. After the imagination task, intolerant (vs. tolerant) norms were manipulated as in Studies 3 and 4, with the fictitious survey allegedly conducted among the Swiss-French population. The same manipulation check showed that respondents in the tolerant norms condition perceived more support for equality $(M=5.05, S D=1.47)$ than respondents in the intolerant norms condition $(M=2.56, S D=$ 1.40), $t(297)=14.99, p<.001$, confirming the success of the experimental manipulation.

Dependent variables. After the experimental manipulations, respondents answered the same intergroup threat measure as in Study $4(\alpha=.87)$ and reported their attitudes toward immigrants, Roma, Arabs, Africans, cross-border workers, and foreign students on feeling thermometers from 0 (extremely unfavorable) to 100 (extremely favorable). We averaged reverse-coded answers to create a composite score of generalized prejudice ( $\alpha=.87$; see supplementary materials for means and standard deviations by experimental condition).

\section{Results and Discussion}

To account and control for the different imagination instructions in the imagined contact experimental manipulation, we created three contrasts. The first contrast (C1) contrasted imagined contact conditions (both coded +1 ) with control conditions (both coded -1) to allow testing our main hypotheses. The second one (C2) was computed to control for the potential differences between control instructions, and therefore contrasted the two control conditions 
$(-1=$ outdoor scene; $+1=$ contact with one parent; imagined contact conditions $=0$ ). The third one (C3) contrasted the two imagined contact conditions to control for the two potential contact targets $(-1=$ imagined contact with an unspecified immigrant; $+1=$ imagined contact with an immigrant from former Yugoslavia; control conditions $=0$ ). Regarding the norms manipulation, as in previous studies, -1 represented tolerant norms, and +1 represented intolerant norms.

We first ran a regression analysis with the three contrasts representing the imagined contact experimental manipulations, intolerant versus tolerant norms, and the two-way interactions between each of the three contrasts and norms as predictors of prejudice. As expected, the interaction term between $\mathrm{C} 1$ and norms on prejudice was significant (see Table 2) and explained 1.4\% of the variance. Exposure to intolerant (vs. tolerant) norms increased generalized prejudice for respondents in the control condition, $B=4.02$, $S E=1.40, p=.004,95 \% \mathrm{CI}[1.27,6.78]$, but not for respondents in the imagined contact condition, $B=0.02, S E=1.36, p=.990,95 \% \mathrm{CI}$ $[-2.67,2.70]$ (see Figure 6). Further, imagined contact reduced prejudice, though at a marginally significant level, for respondents exposed to intolerant norms, $B=-2.31, S E=1.39, p=$ $.098,95 \%$ CI $[-5.06,0.43]$, but not for those exposed to tolerant norms, $B=1.70, S E=1.37$, $p=.217,95 \%$ CI $[-1.00,4.39]$.

The same analysis was run on intergroup threat (see Table 2). Again, the interaction between $\mathrm{C} 1$ and norms was significant and explained $1.5 \%$ of the variance. Intolerant (vs. tolerant) norms increased perceived threat for participants in the control condition, $B=0.27$, $S E=0.09, p=.004,95 \%$ CI [0.08, 0.45], but not for those in the imagined contact condition, $B=$ $-0.01, S E=0.09, p=.939,95 \%$ CI $[-0.18,0.17]$ (see Figure 7). Further, imagined contact reduced perceived threat for respondents exposed to intolerant norms, $B=-0.21, S E=0.09, p=$ $.022,95 \%$ CI $[-0.39,-0.03]$, but not for those exposed to tolerant norms, $B=0.06, S E=0.09$, $p=.493,95 \%$ CI $[-0.12,0.24]$.

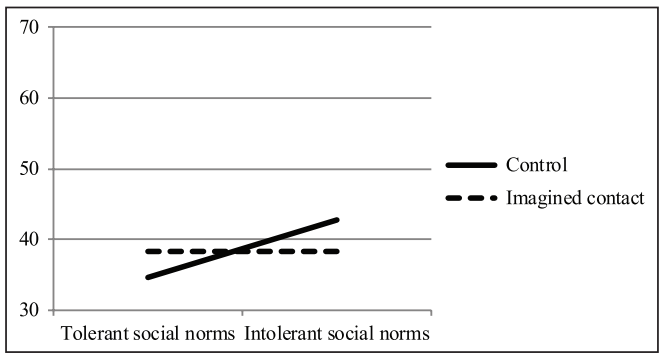

Figure 6. Generalized prejudice as a function of social norms and intergroup contact: Study 5.

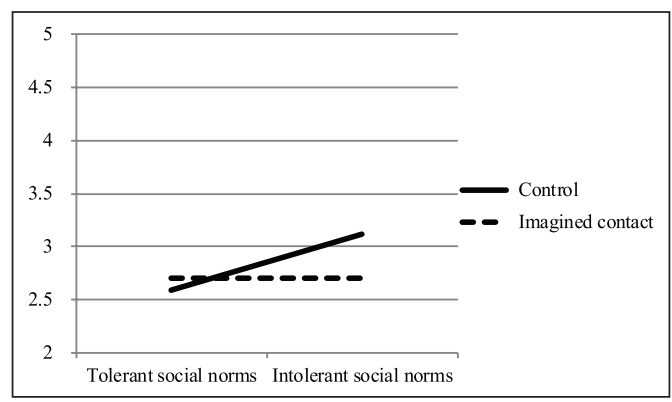

Figure 7. Intergroup threat as a function of social norms and intergroup contact: Study 5.

In the regression analyses, there were also two marginally significant main effects of $\mathrm{C} 3$ on prejudice $(B=-2.62, S E=1.36, p=.055,95 \% \mathrm{CI}$ $[-5.31,0.06])$ and on threat $(B=-0.17, S E=$ $0.09, p=.063,95 \%$ CI $[-0.34,0.01])$. None of the other main or interactive effects were significant $(p s>169)$. The absence of any other significant interaction indicates that the moderating effects of intergroup contact on the dependent variables did not depend on the target outgroup or the control instructions.

Finally, we tested the mediated moderation model with the three contrasts, norms, and the two-way interactions between each contrast and norms as predictors. Intergroup threat was the mediator and prejudice was the dependent variable (Hayes, 2017; Model 8; 95\% bias-corrected bootstrapped CIs based on 5,000 bootstrap samples). As hypothesized, perceived threat mediated the effect of the interaction between $\mathrm{C} 1$ and norms on prejudice, $B=-1.38, S E_{\text {(boot) }}=0.66$, 
$95 \%$ CI $[-2.79,-0.07]$. The indirect effect of intolerant (vs. tolerant) norms on prejudice via perceived threat was significant for respondents in the control condition, $B=2.69, S E_{(\text {boot })}=$ $1.00,95 \%$ CI [0.90, 4.83], but not for respondents in the imagined contact condition, $B=-0.07$, $S E_{\text {(boot) }}=0.87,95 \%$ CI $[-1.72,1.70]$. Further, the interaction between $\mathrm{C} 1$ and norms on prejudice was no longer significant when perceived threat was included in the regression analysis as mediator (see Table 2, last column). None of the other main or interactive effects were significant (ps $>.143)$.

These findings replicated those observed in Study 4 and provided further support for Hypotheses 1 and 2 in a well-powered study using a full experimental design. Specifically, imagined contact moderated the influence of intolerant norms on prejudice and on perceived threat, and perceived threat mediated the effects of the Imagined Contact $x$ Norms interplay on prejudice. The study further showed that such results were independent of the manipulation of imagined intergroup contact (i.e., they did not depend on the target of the imagined encounter or on features of the control condition).

\section{General Discussion}

Across five studies, we demonstrated that intergroup contact moderates the influence of intolerant social norms on prejudice. More specifically, conformity to intolerant norms (i.e., expressing more prejudice when social norms are intolerant rather than tolerant) appeared when intergroup contact was low, whereas participants with high intergroup contact showed less conformity to intolerant social norms. Notably, these findings were obtained whilst using different methodologies (i.e., ranging from large-scale national and cross-national surveys to quasi-experiments and experiments), analyzing different intergroup contexts (i.e., relationships between ethnic groups in Bulgaria, between nationals and immigrants across 21 countries, and between Swiss nationals and immigrants), and using different operationalizations of the key variables. Furthermore, this effect was found both with experiments directly designed and implemented to test this specific hypothesis (Studies 3-5) and by analyzing existing secondary data (Studies 1-2). As the pattern of results was consistent across the five studies, the use of these different methodologies, of both secondary data and original experiments, and the examination of different intergroup contexts provided strong validity to our findings. Furthermore, to our knowledge, this was the first examination of intergroup threat as a possible mediator of the Contact $\times$ Norms interaction effect on prejudice (Studies 4-5). We observed that intergroup threat mediated the effect of the Contact $\times$ Norms interaction on prejudice. Specifically, contact curbs the association between intolerant norms and threat perceptions, which are in turn associated with prejudice.

These findings are relevant to several areas of research, beginning with research on normative influence. Indeed, while norms are powerful determinants of individuals' prejudice and intergroup behavior (e.g., Crandall et al., 2002; Jetten et al., 1996), conformity to norms is not systematic and several moderators have been suggested in the literature (e.g., Blanchard et al., 1994; FalomirPichastor et al., 2004; Jetten et al., 2002). The present research program extends knowledge about influence processes by identifying an additional moderator of conformity to norms: personal contact with outgroup members. Intergroup contact constitutes a direct experience that relates to stronger attitudes and inoculates individuals against the influence of indirect information such as intolerant social norms. Furthermore, the present findings go beyond past research on the influence of tolerant versus intolerant social norms by showing the role of perceived threat in the investigated processes. Indeed, while intolerant social norms may increase prejudice through perceived intergroup threat (Stephan et al., 2009), intergroup contact can reduce this effect.

It is further worth remarking that, by using different operationalizations of norms, we provided evidence for the buffering effect of intergroup contact on different facets of intolerant norms. Some differences nevertheless emerged in 
the result patterns between Studies 1-2 where norms were measured and Studies 3-5 where norms were experimentally manipulated. Specifically, perceived (Study 1) and prevailing (Study 2) intolerant norms were associated with prejudice both for respondents with frequent and for respondents with infrequent contact, but the associations were stronger for those with few contacts. Experimentally manipulated intolerant (vs. tolerant) norms (Studies 3-5) instead increased prejudice only for respondents with low contact (Studies 3-4) or with no imagined contact (Study 5). This suggests that perceived and prevailing norms are strong precursors of prejudice and that their influence on prejudice can be reduced but not fully counteracted by intergroup contact. The experimental manipulations of norms instead, despite being successful and endorsed by respondents as shown by the manipulation checks, consisted of short single-session presentations of information about attitudes and prescribed behaviors of ingroup members. Even though experimentally primed norms impact prejudice, their effects might be more malleable and sensitive to personal experiences with outgroup members.

Our studies also contribute to advancing intergroup contact theory (Pettigrew \& Tropp, 2006) by showing that direct and personal experiences of intergroup contact have the potential of counteracting the effects of a prominent precursor of prejudice, that is, intolerant norms. Intergroup contact was measured with frequency and quantity of (positive) contact items (Studies 1, 3, and 4), as well as cross-group friendships (Study 2). We thus focused on contact facets typically associated with prejudice reduction (Davies et al., 2011; Pettigrew \& Tropp, 2006) and did not include measures of negative intergroup contact (see e.g., Barlow et al., 2012, for the distinction between positive and negative contact). Different predictions could be made for the moderating role of negative contact in the association between norms and prejudice. On the one hand, negative contact is generally associated with more prejudice (Barlow et al., 2012) and it could thus strengthen the positive association between intolerant norms and prejudice. On the other hand, negative contacts are also direct experiences with outgroup members, and people with negative contacts might rely less on secondary information such as tolerant norms. Following the rationale underlying the present research, it could be that conformity to tolerant norms is reduced by negative contact experiences. Thus, future research should focus on the role of negative contact in shaping people's conformity to norms.

Further, we found that merely imagining an interpersonal contact with an unknown outgroup member reduced the influence of norms (Study 5). This finding suggests that imagined contact acts as a first-hand and direct - although fictitious-experience of intergroup contact, which is processed similarly to direct contact experiences (see Crisp \& Turner, 2012). The imagined intergroup contact paradigm has been criticized for possible demand and priming effects (Bigler \& Hughes, 2010), suggesting that respondents might report positive outgroup attitudes following imagined contact to comply with experimenter's request or because of accessibility of the outgroup. Research has nevertheless found that imagined contact can influence outcomes which are not consciously controlled by participants, such as nonverbal behavior (e.g., seating distance; Turner \& West, 2012) and reduction of stressrelated physiological reactions toward outgroups (West, Turner, \& Levita, 2015), and that the imagined contact effects occur also when respondents in the control condition are primed with the outgroup (Turner et al., 2007, Study 2). While the experimental procedure and the explicit prejudice measure used in Study 5 cannot rule out possible alternative interpretations based on social desirability and priming effects, previous research suggests that their impact should be very limited.

Importantly, our results showed that intergroup contact might be particularly effective in reducing prejudice when norms are intolerant (buffering effect of contact; see also JasinskajaLahti et al., 2011; Mähönen et al., 2013). However, other research has suggested that the contactreduced prejudice association might be stronger when norms are tolerant and support positive 
intergroup relations compared to when norms are intolerant (galvanization effect of tolerant norms; for an experimental contact-based intervention, see A. Kende, Tropp, \& Lantos, 2017; for cross-country comparisons, see Green, Visintin, Sarrasin, \& Hewstone, 2019; J. Kende, Phalet, van den Noortgate, Kara, \& Fischer, 2017). While providing consistent evidence for the buffering effect of contact throughout our studies, we acknowledge the existence of the galvanizing effect of tolerant norms. We can only observe differences in operationalizations between studies finding one effect or the other. As regards cross-country comparisons, previous research found that the contact-reduced prejudice association is stronger in countries where policies support positive intergroup relations (Green et al., 2019) and in countries where egalitarian values prevail (J. Kende et al., 2017). Study 2 of the current research program suggests a stronger contact-reduced prejudice association in countries where people highly endorse anti-immigration beliefs. The galvanization effect of tolerant norms thus appears when focusing on policies or on egalitarian values, while the buffering effect of contact was found when focusing on prevailing anti-immigrant norms. Regarding experimental studies, A. Kende et al. (2017), for example, focused on institutional (school) support for the contact intervention, while in Studies 3-5 of the current research program we experimentally manipulated the general normative climate rather than institutional support. The interplay between contact and norms on prejudice thus appears to be complex, and future research should aim at disentangling in which contexts and for which facets of norms one effect is more likely to occur than the other one.

Despite the novelty and importance of our findings, we acknowledge some further caveats of the single studies and of the research program, and propose future research directions. In some studies, we used single-item (for contact in Study 2, for prejudice in Study 3) or two-item measures (for contact and for norms in Study 1). The replication of the result patterns with multiple-item measures in the remaining studies lends confidence to our results. Moreover, while the sample size of Studies 3-4 was relatively low, this limitation was overcome in Study 5, which had an adequate sample size. Finally, in the experiments we contrasted intolerant with tolerant norms, but we did not include neutral control conditions without experimental manipulations of norms. Future studies should replicate our findings with experimental designs including also neutral control conditions to disentangle the direction of effects.

As regards the overall research program, first, the dependent variable throughout our studies was self-reported, explicit prejudice. Future research should test whether intergroup contact moderates the influence of social norms also on subtle or implicit forms of prejudice, as well as on behavioral intentions or actual behavior. Second, we analyzed only the point of view of the dominant majority. To gain further insights into minority-majority relations, future research should also investigate the point of view of minorities. Indeed, on the one hand, minority groups have shared ingroup norms about how to interact with majorities, which are likely to influence minority group members' attitudes (see Branscombe \& Ellemers, 1998; JasinskajaLahti et al., 2011; Mähönen et al., 2013). On the other hand, the contact-reduced prejudice association has been found to be weaker among minority respondents (Tropp \& Pettigrew, 2005). Future research should thus test whether intergroup contact has the potential to reduce the association between intolerant norms and prejudice also among minorities. Finally, we provided evidence for one mechanism mediating the effects of the norms $x$ contact interaction on prejudice, that is, intergroup threat. However, though intergroup threat might be the most relevant mediator when analyzing relationships of ethnic and national majorities with ethnic and immigrant minorities (see Stephan et al., 2009), other mediators should be examined in future research. For example, attitude strength and certainty could be a relevant mediator: Contact should reduce the strength and certainty of attitudes derived from intolerant norms.

Notwithstanding these caveats, through five studies, we demonstrated that the influence of indirect information, such as intolerant norms, 
on prejudice was reduced for people with direct experiences of intergroup contact. Our results call for intergroup contact interventions (see Paluck \& Green, 2009) to counteract intolerant, antiegalitarian viewpoints conveyed by mass media, politicians, and public opinion. Indeed, in settings where a negative outgroup or antiegalitarian stance is the norm (e.g., long-standing conflicts), grassroot-level intergroup interactions may help pave the way towards more harmonious relations between groups.

\section{Authors' note}

Emilio Paolo Visintin's current affiliation is Department of Humanities, University of Ferrara, Italy.

\section{Acknowledgements}

The authors would like to thank Hélène Dubuis, Arianna Gregorio, Natasha Iffland, and Lisa Monnier for their assistance with data collection and coding.

\section{Funding}

The authors disclosed receipt of the following financial support for the research, authorship, and/or publication of this article: This work was supported by the Swiss National Science Foundation (Division 1 Grant No. 100014_159336, awarded to Eva G. T. Green and Juan Manuel Falomir-Pichastor); by the National Center of Competence in Research (NCCR - On the Move Grant No. 51NF40-142020, awarded to Eva G. T. Green and Juan Manuel Falomir-Pichastor); and by the Bulgarian-Swiss Research Programme (Grant No. IZEBZ0_142998, awarded to Eva G. T. Green and Yolanda Zografova).

\section{ORCID iDs}

Emilio Paolo Visintin (iD https://orcid.org/0000-00 03-2250-3533

Juan Manuel Falomir-Pichastor (iD) https://orcid.org /0000-0002-2177-8511

\section{Supplemental material}

Supplemental material for this article is available online.

\section{Notes}

1. Other studies have analyzed the role of normative support in favoring the contact-reduced prejudice association (e.g., A. Kende et al., 2017; Merino, 2013). For example, A. Kende et al. (2017) showed that a contact-based intervention improved Hungarian students' attitudes toward Roma people, especially among those who perceived that their university supported the intervention (i.e., when they perceived positive norms within their institution). In line with Allport's (1954) claim, normative support favored the reduction of prejudice following intergroup contact.

2. Missing values for all studies were imputed with the expectation-maximization algorithm (see Schafer \& Graham, 2002).

3. To ensure independence of measurement between aggregated country-level norms on the one hand and individual-level contact and prejudice on the other hand, we assessed norms with data from a prior survey. We used data from ESS Round 5, because ESS Round 5 provided data for all the countries participating in ESS Round 7 (one of the countries, Austria, participating in ESS Round 7 was absent from ESS Round 6).

4. This question was asked also for the outgroup "immigrants from poorer countries outside Europe." However, as this item was not administered in the Czech Republic, it was excluded from these analyses.

5. The multilevel regression analysis was repeated excluding data from Israel, the only country not on the European continent in ESS Round 7. We also reran the analysis with a five-item composite score of generalized prejudice, excluding the item about Jews, which had low correlations with the other prejudice items in Israel. Results were essentially identical to the main analysis.

6. While Studies 1 and 2 consisted of analyses of secondary data, Studies 3-5 were designed for the current research program. When reporting Studies 3-5, no experimental conditions were omitted. Studies 3-5 included some additional measured variables. Details about the additional measures can be obtained upon request from the first author.

\section{References}

Aiken, L. S., West, S. G., \& Reno, R. R. (1991). Multiple regression: Testing and interpreting interactions. Newbury Park, CA: SAGE.

Allport, G. W. (1954). The nature of prejudice. New York, NY: Addison-Wesley. 
Barlow, F. K., Paolini, S., Pedersen, A., Hornsey, M. J., Radke, H. R., Harwood, J., . . . Sibley, C. G. (2012). The contact caveat: Negative contact predicts increased prejudice more than positive contact predicts reduced prejudice. Personality and Social Psychology Bulletin, 38, 1629-1643. doi: $10.1177 / 0146167212457953$

Bigler, R. S., \& Hughes, J. M. (2010). Reasons for skepticism about the efficacy of simulated social contact interventions. American Psychologist, 65, 132-133. doi:10.1037/a0018097

Blanchard, F. A., Crandall, C. S., Brigham, J. C., \& Vaughn, L. A. (1994). Condemning and condoning racism: A social context approach to interracial settings. Journal of Applied Psychology, 79, 993-997. doi:10.1037/0021-9010.79.6.993

Branscombe, N. R., \& Ellemers, N. (1998). Coping with group-based discrimination: Individualistic versus group-level strategies. In J. K. Swim \& C. Stangor (Eds.), Prejudice: The target's perspective (pp. 243-266). San Diego, CA: Academic Press.

Brown, R., \& Hewstone, M. (2005). An integrative theory of intergroup contact. Advances in Experimental Social Psychology, 37, 255-343. doi:10.1016/S0065 -2601(05)37005-5

Ceobanu, A. M., \& Escandell, X. (2010). Comparative analyses of public attitudes toward immigrants and immigration using multinational survey data: A review of theories and research. Annual Review of Sociology, 36, 309-328. doi:10.1146/annurev. soc.012809.102651

Christ, O., Schmid, K., Lolliot, S., Swart, H., Stolle, D., Tausch, N., . . . Hewstone, M. (2014). Contextual effect of positive intergroup contact on outgroup prejudice. Proceedings of the National Academy of Sciences, 111, 3996-4000. doi:10.1073/ pnas.1320901111

Cialdini, R. B., Kallgren, C. A., \& Reno, R. R. (1991). A focus theory of normative conduct: A theoretical refinement and reevaluation of the role of norms in human behavior. Advances in Experimental Social Psychology, 24, 201-234. doi:10.1016/S0065 $-2601(08) 60330-5$

Crandall, C. S., Eshleman, A., \& O'Brien, L. (2002). Social norms and the expression and suppression of prejudice: The struggle for internalization. Jour nal of Personality and Social Psychology, 82, 359-378. doi:10.1037/0022-3514.82.3.359

Crisp, R. J., \& Turner, R. N. (2012). The imagined contact hypothesis. Advances in Experimental Social Psychology, 46, 125-182. doi:10.1016/B978-0-12 -394281-4.00003-9
Davies, K., Tropp, L. R., Aron, A., Pettigrew, T. F., \& Wright, S. C. (2011). Cross-group friendships and intergroup attitudes: A meta-analytic review. Personality and Social Psychology Review, 15, 332-351. doi: $10.1177 / 1088868311411103$

Dhont, K., \& van Hiel, A. (2012). Intergroup contact buffers against the intergenerational transmission of authoritarianism and racial prejudice. Journal of Research in Personality, 46, 231-234. doi:10.1016/j .jrp.2011.12.008

Dovidio, J. F., \& Gaertner, S. L. (2004). Aversive racism. Advances in Experimental Social Psychology, 36, 1-51. doi:10.1016/S0065-2601(04)36001-6

Enders, C. K., \& Tofighi, D. (2007). Centering predictor variables in cross-sectional multilevel models: A new look at an old issue. Psychological Methods, 12, 121-138. doi:10.1037/1082-989X.12.2.121

European Social Survey (ESS). (2010). ESS 5 - 2010 data download. Retrieved from https://www.euro peansocialsurvey.org/data/download.html? $\mathrm{r}=5$

European Social Survey (ESS). (2014). ESS 7 - 2014 data download. Retrieved from https://www.euro peansocialsurvey.org/data/download.html? $\mathrm{r}=7$

Falomir-Pichastor, J. M., Gabarrot, F., Mugny, G., \& Nurra, C. (2007). Influence normative, menace intergroupe et adaptabilité perçue des immigrés [Normative influence, intergroup threat, and perceived adaptability of immigrants]. Bulletin de Psychologie, 491, 407-414. doi:10.3917 /bupsy.491.0407

Falomir-Pichastor, J. M., \& Mugny, G. (2009). Influencia social y discriminación: Percepción de la capacidad de adaptación de los inmigrantes y amenaza para la identidad nacional [Social influence and discrimination: Perceived adaptability of immigrants and threat to national identity]. Revista de Psicología Social, 24, 3-15. doi:10.1174/021347409786922943

Falomir-Pichastor, J. M., Muñoz-Rojas, D., Invernizzi, F., \& Mugny, G. (2004). Perceived in-group threat as a factor moderating the influence of in-group norms on discrimination against foreigners. European Journal of Social Psychology, 34, 135-153. doi:10.1002/ejsp.189

Faul, F., Erdfelder, E., Lang, A. G., \& Buchner, A. (2007). G*Power 3: A flexible statistical power analysis program for the social, behavioral, and biomedical sciences. Behavior Research Methods, 39 , 175-191. doi:10.3758/BF03193146

Fazio, R. H. (1990). Multiple processes by which attitudes guide behavior: The MODE model as an integrative framework. Advances in Experimental Social Psychology, 23, 75-109. doi:10.1016/s0065 -2601(08)60318-4 
Fazio, R. H., Zanna, M. P., \& Cooper, J. (1978). Direct experience and attitude-behavior consistency: An information processing analysis. Personality and Social Psychology Bulletin, 4, 48-51. doi:10.1177/014616727800400109

Giacobbe, M. R., Stukas, A. A., \& Farhall, J. (2013). The effects of imagined versus actual contact with a person with a diagnosis of schizophrenia. Basic and Applied Social Psychology, 35, 265-271. doi:10.1 080/01973533.2013.785403

Green, E. G. T. (2009). Who can enter? A multilevel analysis on public support for immigration criteria across 20 European countries. Group Processes \& Intergroup Relations, 12, 41-60. doi:10.1177/1368430209102208

Green, E. G. T., Visintin, E. P., Sarrasin, O., \& Hewstone, M. (2019). When integration policies shape the impact of intergroup contact on threat perceptions: A multilevel study across 20 European countries. Journal of Ethnic and Migration Studies. Advance online publication. doi:10.1080/13691 83x.2018.1550159

Green, E. G. T., \& Zografova, Y. (2014). Interethnic relations in Bulgaria. Unpublished dataset.

Greven, T. (2016). The rise of right-wing populism in Europe and the United States. Berlin, Germany: FriedrichEbert-Stiftung.

Hayes, A. F. (2017). Introduction to mediation, moderation, and conditional process analysis: A regression-based approach (2nd ed.). New York, NY: Guilford Press.

Hornsey, M. J., Majkut, L., Terry, D. J., \& McKimmie, B. M. (2003). On being loud and proud: Nonconformity and counter-conformity to group norms. British Journal of Social Psychology, 42, 319335. doi:10.1348/014466603322438189

Howe, L. C., \& Krosnick, J. A. (2017). Attitude strength. Annual Review of Psychology, 68, 327-351. doi:10.1146/annurev-psych-122414-033600

Jasinskaja-Lahti, I., Mähönen, T. A., \& Liebkind, K. (2011). Ingroup norms, intergroup contact and intergroup anxiety as predictors of the outgroup attitudes of majority and minority youth. International Journal of Intercultural Relations, 35, 346-355. doi:10.1016/j.ijintrel.2010.06.001

Jetten, J., \& Hornsey, M. J. (2014). Deviance and dissent in groups. Annual Review of Psychology, 65, 461485. doi:10.1146/annurev-psych-010213-115151

Jetten, J., Postmes, T., \& McAuliffe, B. J. (2002). "We're all individuals": Group norms of individualism and collectivism, levels of identification and identity threat. European Journal of Social Psychology, 32, 189-207. doi:10.1002/ejsp.65
Jetten, J., Spears, R., \& Manstead, A. S. (1996). Intergroup norms and intergroup discrimination: Distinctive self-categorization and social identity effects. Journal of Personality and Social Psychology, 71, 1222-1233. doi:10.1037/0022-3514.71.6.1222

Kende, A., Tropp, L., \& Lantos, N. A. (2017). Testing a contact intervention based on intergroup friendship between Roma and non-Roma Hungarians: Reducing bias through institutional support in a non-supportive societal context. Journal of Applied Social Psychology, 47, 47-55. doi:10.1111 /jasp.12422

Kende, J., Phalet, K., van den Noortgate, W., Kara, A., \& Fischer, R. (2017). Equality revisited: A cross-cultural meta-analysis of the contact hypothesis. Social Psychological and Personality Science. Advance online publication. doi:10.1177/1948550617728993

Laurence, J. (2014). Reconciling the contact and threat hypotheses: Does ethnic diversity strengthen or weaken community inter-ethnic relations? Ethnic and Racial Studies, 37, 1328-1349. doi:10.1080/01 419870.2013 .788727

Leidner, B., Castano, E., Zaiser, E., \& Giner-Sorolla, R. (2010). Ingroup glorification, moral disengagement, and justice in the context of collective violence. Personality and Social Psychology Bulletin, 36, 1115-1129. doi:10.1177/0146167210376391

Levin, S., Matthews, M., Guimond, S., Sidanius, J., Pratto, F., Kteily, N., ... Dover, T. (2012). Assimilation, multiculturalism, and colorblindness: Mediated and moderated relationships between social dominance orientation and prejudice. Journal of Experimental Social Psychology, 48, 207-212. doi:10.1016/j.jesp.2011.06.019

Mähönen, T. A., Ihalainen, K., \& Jasinskaja-Lahti, I. (2013). Specifying the contact hypothesis in a minority-minority context: A social identity perspective. Zeitschrift für Psychologie, 221, 223-231. doi:10.1027/2151-2604/a000152

Mazzoleni, O., \& Pilotti, A. (2015). The outcry of the periphery? An analysis of Ticino's no to immigration. Swiss Political Science Review, 21, 63-75. doi:10.1111/spsr.12147

McConahay, J. B. (1986). Modern racism, ambivalence, and the Modern Racism Scale. In J. F. Dovidio \& S. L. Gaertner (Eds.), Prejudice, discrimination, and racism (pp. 91-125). San Diego, CA: Academic Press.

Merino, S. M. (2013). Contact with gays and lesbians and same-sex marriage support: The moderating role of social context. Social Science Research, 42, 1156-1166. doi:10.1016/j.ssre search.2013.02.004 
Miles, E., \& Crisp, R. J. (2014). A meta-analytic test of the imagined contact hypothesis. Group Processes \& Intergroup Relations, 17, 3-26. doi: $10.1177 / 1368430213510573$

Mudde, C. (2013). Three decades of populist radical right parties in Western Europe: So what? European Journal of Political Research, 52, 1-19. doi:10.1111/j.1475-6765.2012.02065.x

Muthén, L. K., \& Muthén, B. (1998-2012). Mplus user's guide (7th ed.). Los Angeles, CA: Author.

Mutz, D. C., \& Goldman, S. K. (2010). Mass media. In J. F. Dovidio, M. Hewstone, P. Glick \& V. M. Esses (Eds.), The Sage handbook of prejudice, stereotyping and discrimination (pp. 241-258). London, UK: SAGE.

Nicolet, S., \& Sciarini, P. (2006). When do issue opinions matter, and to whom? The determinants of longterm stability and change in party choice in the 2003 Swiss elections. Swiss Political Science Review, 12, 159-190. doi:10.1002/j.1662-6370.2006. tb00064.x

Packer, D. J., \& Chasteen, A. L. (2010). Loyal deviance: Testing the normative conflict model of dissent in social groups. Personality and Social Psychology Bulletin, 36, 5-18. doi:10.1177/0146167209350628

Paluck, E. L., \& Green, D. P. (2009). Prejudice reduction: What works? A review and assessment of research and practice. Annual Review of Psychology, 60, 339-367. doi:10.1146/annurev. psych.60.110707.163607

Pettigrew, T. F., Christ, O., Wagner, U., \& Stellmacher, J. (2007). Direct and indirect intergroup contact effects on prejudice: A normative interpretation. International Journal of Intercultural Relations, 31, 411425. doi:10.1016/j.ijintrel.2006.11.003

Pettigrew, T. F., \& Meertens, R. W. (1995). Subtle and blatant prejudice in Western Europe. European Journal of Social Psychology, 25, 57-75. doi:10.1002 /ejsp.2420250106

Pettigrew, T. F., \& Tropp, L. R. (2006). A meta-analytic test of intergroup contact theory. Journal of Personality and Social Psychology, 90, 751-783. doi:10.1037/0022-3514.90.5.751

Pettigrew, T. F., \& Tropp, L. R. (2008). How does intergroup contact reduce prejudice? Meta-analytic tests of three mediators. European Journal of Social Psychology, 38, 922-934. doi:10.1002/ejsp.504

Riek, B. M., Mania, E. W., \& Gaertner, S. L. (2006). Intergroup threat and outgroup attitudes: A meta-analytic review. Personality and Social Psychology Review, 10, 336-353. doi:10.1207/s15327957 pspr1004_4
Rios, K., Wheeler, S. C., \& Miller, D. T. (2012). Compensatory nonconformity: Self-uncertainty and low implicit self-esteem increase adoption and expression of minority opinions. Journal of Experimental Social Psychology, 48, 1300-1309. doi:10.1016/j.jesp.2012.07.005

Rodríguez-García, J.-M., \& Wagner, U. (2009). Learning to be prejudiced: A test of unidirectional and bidirectional models of parentoffspring socialization. International Journal of Intercultural Relations, 33, 516-523. doi:10.1016/j. ijintrel.2009.08.001

Schafer, J. L., \& Graham, J. W. (2002). Missing data: Our view of the state of the art. Psychological Methods, 7, 147-177. doi:10.1037/1082-989X.7.2.147

Schmid, K., Al Ramiah, A., \& Hewstone, M. (2014). Neighborhood ethnic diversity and trust: The role of intergroup contact and perceived threat. Psychological Science, 25, 665-674. doi:10.1177/0956797613508956

Sechrist, G.B., \&Stangor, C. (2007). When areintergroup attitudes based on perceived consensus information? The role of group familiarity. Social Influence, 2, 211-235. doi:10.1080/15534510701459068

Stephan, W. G., Boniecki, K. A., Ybarra, O., Bettencourt, A., Ervin, K. S., Jackson, L. A., . . . Renfro, C. L. (2002). The role of threats in the racial attitudes of Blacks and Whites. Personality and Social Psychology Bulletin, 28, 1242-1254. doi:10.1177/01461672022812009

Stephan, W. G., Ybarra, O., \& Rios Morrison, K. (2009). Intergroup threat theory. In T. Nelson (Ed.), Handbook of prejudice, stereotyping, and discrimination (pp. 43-59). Mahwah, NJ: Lawrence Erlbaum Associates.

Swart, H., Hewstone, M., Christ, O., \& Voci, A. (2011). Affective mediators of intergroup contact: A three-wave longitudinal study in South Africa. Journal of Personality and Social Psychology, 101, 12211238. doi: $10.1037 / \mathrm{a} 0024450$

Swiss Federal Statistical Office (SFSO). (2017). Rapport statistique sur l'intégration de la population issue de la migration [Statistical report on integration of population with migration background]. Retrieved from https://www.bfs.admin.ch/bfs/fr/home / statistiques/population/migration-integration /indicateurs-integration.assetdetail.2546311.html

Tankard, M. E., \& Paluck, E. L. (2016). Norm perception as a vehicle for social change. Social Issues and Policy Review, 10, 181-211. doi:10.1111/ sipr.12022 
Tausch, N., Tam, T., Hewstone, M., Kenworthy, J., \& Cairns, E. (2007). Individual-level and group-level mediators of contact effects in Northern Ireland: The moderating role of social identification. British Journal of Social Psychology, 46, 541-556. doi: 10.1348/014466606X155150

Thomsen, J. P. F., \& Rafiqi, A. (2018). When does superficial intergroup contact reduce anti-foreigner sentiment? Negative contact as an essential condition. International Journal of Comparative Sociology, 59, 25-43. doi:10.1177/0020715217744598

Tropp, L. R., \& Pettigrew, T. F. (2005). Relationships between intergroup contact and prejudice among minority and majority status groups. Psychological Science, 16, 951-957. doi:10.1111/j.14679280.2005.01643.x

Turner, R. N., Crisp, R. J., \& Lambert, E. (2007). Imagining intergroup contact can improve intergroup attitudes. Group Processes \& Intergroup Relations, 10, 427-441. doi:10.1177/1368430207081533

Turner, R. N., \& West, K. (2012). Behavioural consequences of imagining intergroup contact with stigmatized outgroups. Group Processes \& Intergroup Relations, 15, 193-202. doi:10.1177/1368430211 418699

Van Assche, J., Roets, A., De Keersmaecker, J., \& van Hiel, A. (2017). The mobilizing effect of right-wing ideological climates: Cross-level interaction effects on different types of outgroup attitudes. Political Psychology, 38, 757-776. doi:10.1111/pops.12359

Vassilev, R. (2010). Restoring the ethnolinguistic rights of Bulgaria's Turkish minority. Ethnopolitics, 9, 295-309. doi:10.1080/17449050903551859
Vezzali, L., Crisp, R. J., Stathi, S., \& Giovannini, D. (2013). The affective consequences of imagined contact: A review and some suggestions for future research. TPM: Testing, Psychometrics, Methodology in Applied Psychology, 20, 343-363. doi:10.4473/TPM20.4.4

Vezzali, L., Stathi, S., Crisp, R. J., \& Capozza, D. (2015). Comparing direct and imagined intergroup contact among children: Effects on outgroup stereotypes and helping intentions. International Journal of Intercultural Relations, 49, 46-53. doi:10.1016/j .ijintrel.2015.06.009

Visintin, E. P., Berent, J., Green, E. G. T., \& FalomirPichastor, J. M. (2019). The interplay between social dominance orientation and intergroup contact in explaining support for multiculturalism. Journal of Applied Social Psychology, 49, 319-327. doi:10.1111/jasp.12587

Voci, A., \& Hewstone, M. (2003). Intergroup contact and prejudice toward immigrants in Italy: The mediational role of anxiety and the moderational role of group salience. Group Processes \& Intergroup Relations, 6, 37-54. doi:10.1177/1368430203006001011

Vonofakou, C., Hewstone, M., \& Voci, A. (2007). Contact with out-group friends as a predictor of meta-attitudinal strength and accessibility of attitudes toward gay men. Journal of Personality and Social Psychology, 92, 804-820. doi:10.1037/0022-3514.92.5.804

West, K., Turner, R., \& Levita, L. (2015). Applying imagined contact to improve physiological responses in anticipation of intergroup interactions and the perceived quality of these interactions. Journal of Applied Social Psychology, 45, 425-436. doi:10.1111/jasp.12309 